\title{
Binding of hydrothermally processed starch to $\alpha$-amylase and its relation to the kinetics of enzyme digestion
}

\author{
H. Patel, P. Ellis and P. Butterworth \\ School of Medicine, King's College London, London, SE1 9NH, UK
}

Starch is the main source of digestible carbohydrates and contributes significantly to the total food energy intake in the human diet. Many researchers have been interested in starch digestion due to the marked increase in postprandial blood glucose and insulin concentrations following a starch-rich meal ${ }^{(1)}$. Starches which have been heated and stored are digested at a much slower rate compared to starches which have been heated and immediately used due to the process of retrogradation ${ }^{(2)}$. The purpose of this mechanistic research project is to produce kinetic data $\left(K_{\mathrm{m}}\right.$ and $\left.k_{\mathrm{cat}} / K_{\mathrm{m}}\right)$ that provides an improved understanding of the initial interaction between $\alpha$-amylase and retrograded starch.

Native, gelatinised (heated at $90^{\circ} \mathrm{C}$ ) and retrograded (stored over a time period of 24-96h at room temperature) wheat, potato and pea starch forms were digested with $\alpha$-amylase to produce digestibility curves $(n=4)$. The $K_{\mathrm{m}}$ and $k_{\text {cat }} / K_{\mathrm{m}}$ were then determined from these digestibility plots, with the $K_{\mathrm{m}}$ representing the $\alpha$-amylase affinity and $k_{\mathrm{cat}} / K_{\mathrm{m}}$ indicating the catalytic efficiency ${ }^{(2)}$. Following hydrothermal treatment of the starch samples, the $k_{\mathrm{cat}} / K_{\mathrm{m}}$ increased drastically compared to the native samples, as shown in Figure 1 . The sharp rise in $k_{\mathrm{cat}} / K_{\mathrm{m}}$ is most probably due to the loss of the ordered $\alpha$-glucan structure and the corresponding increase in the quantity of amorphous material. For retrograded wheat and potato samples, the $k_{\mathrm{cat}} / K_{\mathrm{m}}$ reduced relative to no cooling. However $k_{\mathrm{cat}} / K_{\mathrm{m}}$ for pea starch only starts to reduce after $72 \mathrm{~h}$ suggesting retrogradation begins later compared to wheat and potato starch. Surprisingly, the binding of $\alpha$-amylase to starch does not change over $96 \mathrm{~h}$; as indicated by the $K_{\mathrm{m}}$ values (Figure 2). These results suggest retrograded starch may act as a competitive inhibitor due to the constant $K_{\mathrm{m}}$ and reducing $k_{\text {cat }} / K_{\mathrm{m}}{ }^{(3)}$. No change in $K_{\mathrm{m}}$ suggests $\alpha$-amylase still binds to retrograded starch but the hydrolysis step does not occur hence the decrease in $k_{\mathrm{cat}} / K_{\mathrm{m}}$. These results highlight the potential relevance of resistant and slowly-digestible starch in health and disease (e.g. management of type 2 diabetes).

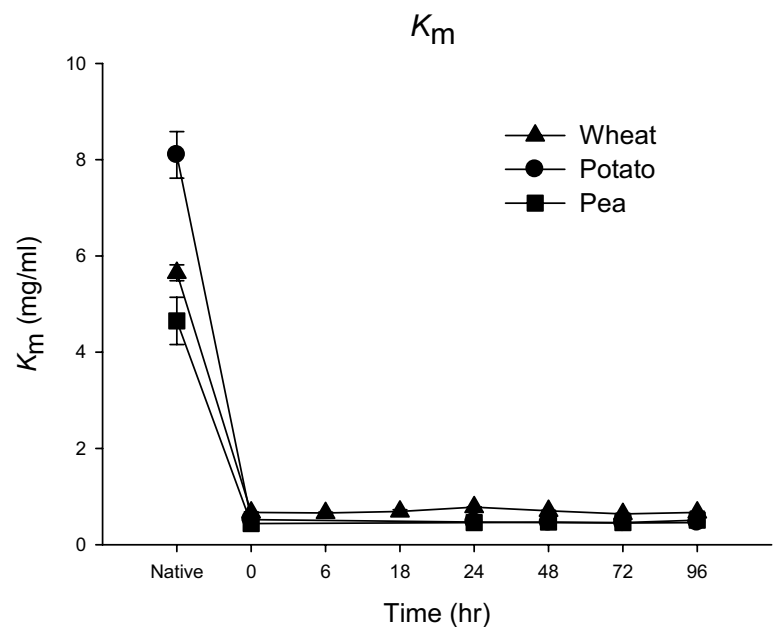

Fig. 1. $K_{\mathrm{m}}$ for the digestion of wheat, potato and pea starch.

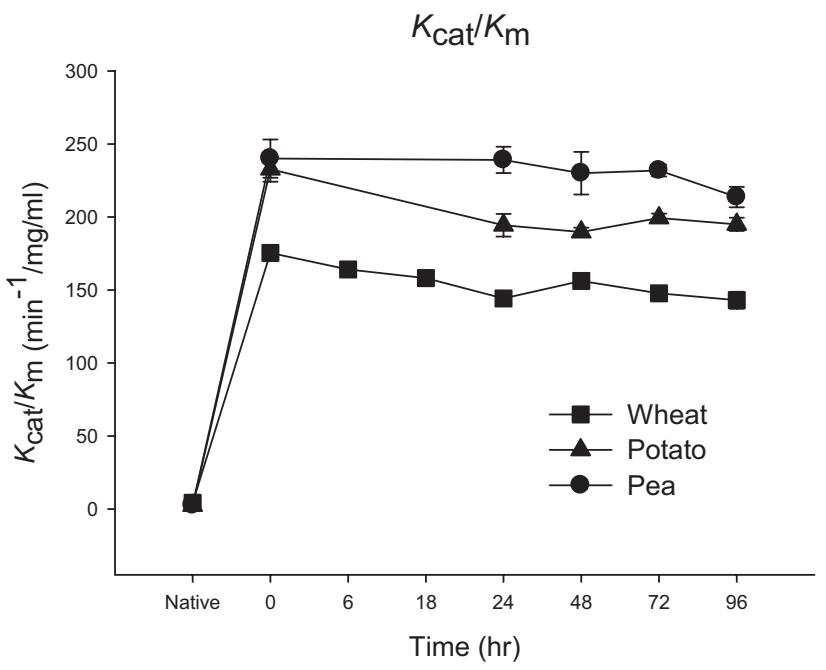

Fig. 2. $K_{\text {cat }} / K_{\mathrm{m}}$ for the digestion of wheat, potato and pea starch.

1. Butterworth P, Warren F, Grassby T et al. (2012) Carbohydr Polym 87, 2189-2197.

2. Slaughter S, Ellis P \& Butterworth P (2000) Carbohydr Polym 1525, 29-36.

3. Bustos M, Barrera G, Perez G et al. (2012) Int J Food Sci tech 47, 2134-2140. 